NBER WORKING PAPER SERIES

\title{
LABOR DEMAND IN THE TIME OF COVID-19: EVIDENCE FROM VACANCY POSTINGS AND UI CLAIMS
}

\author{
Eliza Forsythe \\ Lisa B. Kahn \\ Fabian Lange \\ David G. Wiczer \\ Working Paper 27061 \\ http://www.nber.org/papers/w27061
NATIONAL BUREAU OF ECONOMIC RESEARCH
1050 Massachusetts Avenue
Cambridge, MA 02138
April 2020

We thank Dan Restuccia, Matt Sigelman, and Bledi Taska for providing the Burning Glass Technologies data, as well as Shiwani Chitroda, Nathan Maves-Moore and Fan Xia for excellent research assistance. This research was undertaken, in part, thanks to funding from the Canada Research Chairs program. The views expressed herein are those of the authors and do not necessarily reflect the views of the National Bureau of Economic Research.

NBER working papers are circulated for discussion and comment purposes. They have not been peerreviewed or been subject to the review by the NBER Board of Directors that accompanies official NBER publications.

(C) 2020 by Eliza Forsythe, Lisa B. Kahn, Fabian Lange, and David G. Wiczer. All rights reserved. Short sections of text, not to exceed two paragraphs, may be quoted without explicit permission provided that full credit, including $(\odot)$ notice, is given to the source. 
Labor Demand in the time of COVID-19: Evidence from vacancy postings and UI claims

Eliza Forsythe, Lisa B. Kahn, Fabian Lange, and David G. Wiczer

NBER Working Paper No. 27061

April 2020, Revised August 2020

JEL No. J23,J6,J63

\begin{abstract}
We use job vacancy data collected in real time by Burning Glass Technologies, as well as unemployment insurance (UI) initial claims and the more traditional Bureau of Labor Statistics (BLS) employment data to study the impact of COVID-19 on the labor market. Our job vacancy data allow us to track the economy at disaggregated geography and by detailed occupation and industry. We find that job vacancies collapsed in the second half of March. By late April, they had fallen by over $40 \%$. To a first approximation, this collapse was broad based, hitting all U.S. states, regardless of the timing of stay-at-home policies. UI claims and BLS employment data also largely match these patterns. Nearly all industries and occupations saw contraction in postings and spikes in UI claims, with little difference depending on whether they are deemed essential and whether they have work-from-home capability. Essential retail, the "front line" job most in-demand during the current crisis, took a much smaller hit, while leisure and hospitality services and non-essential retail saw the biggest collapses. This set of facts suggests the economic collapse was not caused solely by the stay-at-home orders, and is therefore unlikely to be undone simply by lifting them.
\end{abstract}

Eliza Forsythe

University of Illinois, Urbana-Champaign 504 East Armory Avenue

Champaign, IL 61821

eforsyth@illinois.edu

Lisa B. Kahn

Department of Economics

University of Rochester

280 Hutchison Rd

P.O. Box 270156

Rochester, NY 14627

and NBER

lisa.kahn@ rochester.edu
Fabian Lange

Department of Economics

McGill University

855 Sherbrooke Street West

Montreal QC H3A, 2T7

and NBER

fabian.lange@mcgill.ca

David G. Wiczer

Stony Brook University

100 Nicolls Rd

Economics Department, S617 SBS

Stony Brook, NY 11794

david.wiczer@stonybrook.edu 


\section{Labor Demand in the time of COVID-19: Evidence from vacancy postings and UI claims}

\author{
Eliza Forsythe \\ University of Illinois
}

\author{
Lisa B. Kahn \\ University of Rochester, \\ NBER and IZA \\ David Wiczer* \\ Stony Brook University
}

June 182020

\author{
Fabian Lange \\ McGill University, \\ NBER and IZA
}


UI claims data however is highly aggregated, with only a few states reporting claims across industries. As such, UI claims provide a coarse filter through which to assess the state of the labor market. Thanks to Burning Glass Technologies (BGT), a company that scrapes, cleans, and codes job vacancies posted on the internet at a daily frequency, we can gain a deeper understanding of how the labor market evolved over the COVID crisis. Both data sources have the advantage of being available in close-to real time. With hindsight, we can compare these series to the more traditional Bureau of Labor Statistics (BLS) employment situation, released on a monthly basis.

UI claims data and vacancy data measure fundamentally distinct phenomena. The former give an indication of how many matches in the labor market have become unsustainable over a given period. ${ }^{1}$ By contrast, vacancies provide a forward looking measure as firms post vacancies to establish new employment relationships.

In this report, we analyze both UI claims data and vacancy data from Burning Glass Technologies to provide a more detailed account of how the labor market deteriorated over March and April, 2020 and ask how broad-based it was. After our initial writing, the BLS employment situation data were released, enabling us to validate our initial analyses.

We find:

1. Vacancy postings collapsed by $44 \%$ between February and April. The timing coincided with a spikes in initial UI claims and exits to non-employment, and a $13 \%$ crash in employment.

2. To a first approximation, the labor market collapsed at the same time across the U.S. irrespective of the state-level policies imposed. There is little evidence that labor markets in states that imposed stay-at-home orders earlier were differentially affected. In contrast, there is some evidence that states hit more heavily by the early spread of the virus took a bigger labor market hit.

3. The labor market was in broad retreat across almost all industries, whether they are deemed essential or non-essential. The main exception is for essential retail, which saw no decline in postings and smaller, though still pronounced, spikes in claims. As a result, these areas will see substantial labor reallocation.

4. The labor market collapsed across occupations, regardless of work conditions. Occupations that lend themselves to working from home did see a slightly smaller spike in UI claims and employment contraction, but experienced a similar decline in job postings, compared to jobs where working from home is likely not possible.

Given the magnitude of the economic shock, an important set of papers are providing contemporaneous, complementary evidence on the extent and synchronicity of the deterioration of

\footnotetext{
${ }^{1}$ Claims data, will however, only measure cases in which a job is dissolved and the employee is eligible for benefits. Workers who move directly to another job or out of the labor force, and those who are fired for cause are ineligible and will not show up in the claims data. Further, take-up rates among the eligible are likely well less than $100 \%$ ([Blank and Card, 1991]).
} 
the labor market. One area addresses the need for more granular, timely unemployment data by conducting new surveys that ask respondents about their labor force status (Adams-Prassl et al. [2020], Blandin and Bick [2020] and Coibion et al. [2020]). These surveys all suggest a massive increase in separations. Cajner et al. [2020] further corroborates the intensive and broadly spread employment collapse using data from ADP, a large payroll company and Baek et al. [2020] and Gupta et al. [2020] also show that unemployment insurance claims were mostly unresponsive to state-level policy. Cortes and Forsythe [n.d.] use individual panels to show some heterogeneity, with larger losses among the already poor, but still a very widespread decline. A second set of studies provides context to the collapse in vacancies we observe. Hassan et al. [2020], Baker et al. [2020], Bartik et al. [2020] along with Barrero et al. [2020] inform the difficulties of firms, who face both uncertainty and lower expected demand and are often too constrained to smooth over the shock. These papers provide a rationale for why firms would understandably be reluctant to post a vacancy, essentially a costly investment to expand labor.

We contribute to this literature by providing a rich glimpse into the employment picture with detailed, real-time data on job vacancies. Complementing our analysis of vacancies, Campello et al. [2020] use a different source of vacancies but see a similar overall decline, adding that the decline is worse among small firms and high skill occupations while Hensvik et al. [2020] show the same massive decline of postings in Sweden.

We show the U.S. labor market experienced unprecedented weakness. The broad-based nature of the collapse in vacancy postings and spikes in UI claims suggest the current damage is not solely caused by stay-at-home orders. Instead, the deterioration of the labor market is a national phenomenon driven by a national crisis and is, if anything, more closely related to the spread of the virus itself than to state policies. Furthermore, sectors are experiencing similar collapses whether they are directly restricted or only indirectly affected. We therefore conclude that the damage to the economy is unlikely to be undone simply by lifting stay-at-home orders.

\section{Data and Methods}

\section{Burning Glass Job Postings}

We obtain data on job vacancy postings from Burning Glass Technologies (BGT), an employment analytics and labor market information firm. BGT scrapes, parses and codes electronic postings from over 40,000 online job boards and company websites to obtain what they believe is the nearuniverse of jobs that were posted online. The ad-level data were first used by Hershbein and Kahn [2018] to show that the Great Recession accelerated adoption of labor-replacing technologies.

Currently BGT are producing ad-level data with a lag of only a day or two. The data in this paper go through the last week in April 2020 (the week ending May 2). Further, BGT characterize over 70 possible standardized fields per vacancy, including the location, industry, and occupation of the job posting. BGT data thus provide us with rich and timely data on the demand of labor during the COVID-19 crisis. 
The major downside of the data are that they only cover jobs posted to online sources. While online vacancies are increasingly common, they do over-represent higher skilled occupations and industries. Reassuringly, Dalton et al. [2020] link BGT job ads to the Job Openings and Labor Turnover Survey at the establishment level and find a great deal of alignment across the two datasets.

\section{Initial Unemployment Insurance Claims}

We obtain initial unemployment insurance (UI) claims data from the U.S. Department of Labor, the FRED database as well as states' own department of labor websites. Claims data in this paper also go through the end of April.

UI claims data are advantageous in that they should include the universe of claims processed. However, because the microdata is confidential, they are available at much less detail than BGT job postings. Anecdotal reports also suggest that some state systems were overloaded in late March and early April and could not process as many claims as the number attempting to file. Thus, in some states the data might show a more gradual increase in initial claims relative to the actual spike in displacements.

\section{Bureau of Labor Statistics Employment Situation}

The BLS household and employer surveys provide the traditional and most closely followed metrics of labor market well-being. The summary Employment Situation is released on a monthly basis, and employment statistics refer to the status as of the week in the month that contains the 12th. Incidentally, this means that the March data was largely collected just prior to shutdown of much the US economy. The April data, released in early May, was the first of the traditional BLS data released that covered the collapse of the labor market in mid March.

We use the Current Employment Statistics (CES) to generate employment series that are based on a large representative survey of employers, the "payroll survey". These data can be disaggregated by state and by industry. We also use Current Population Survey (CPS) microdata, that stem from the household survey, to calculate separations from employment to non-employment using the longitudinal link. This CPS exits series has the advantage that it will capture layoffs where the worker is not eligible to collect UI (or workers on UI whose state systems have not been able to clear them yet) and also contains industry and occupation information. However, sample sizes are small and not all exits to non-employment are involuntary.

These series were added to our paper well after our BGT and UI analyses were complete and therefore provide a useful cross-check for the less traditional BGT data source, which is available at much greater frequency and much more detail. 


\section{Findings}

Appendix Figure A.1 has time series for four measures of labor market well-being: BG job postings, CES employment, UI initial claims, and the CPS exit rate to non-employment.

From Burning Glass Technologies, we observe a steep decline in job postings beginning in mid March. The number of weekly postings fell from 815 thousand in the week of March 15 to 460 thousand in the week of April 26, a 44\% drop. To put this number in perspective, over the Great Recession, the total number of vacancies in the U.S. declined by $50 \%$ in the 1.5 year time interval from recessionary peak to trough. The CES employment series shows a $13 \%$ drop in employment over the same time period. In the Great Recession, employment fell by $6.3 \%$ from peak to trough. ${ }^{2}$

The declines in vacancies and employment coincide with a sharp rise in UI claims beginning in the week of March 15th. Claims peaked in the last full week of March and declined gradually over April. Nevertheless, initial claims still remain at historically high levels. Between mid-March and the second half of April over 30 million initial claims filed. The CPS tells us that the rate of exit from employment to non-employment (which would include workers ineligible or unable to sign up for benefits) increased from 3.5\% in February to nearly $20 \%$ in April. ${ }^{3}$ Recent research has found that the majority of these separations were reported as temporary ( Kudlyak and Wolcott [2020], Barrero et al. [2020]).

\section{Variation across U.S. States}

Figure 1 summarizes variation in experiences across the U.S.. We collect states into four groups based on the timing of their state-issued stay-at-home orders. All series give the per capita change from the beginning-of-year level (January 19-February 29, 2020). The color coordinated vertical lines indicate the week in which the first stay-at-home order in the state policy group was given (see figure note).

Interestingly, the timing and magnitude of the labor market responses are similar across states that differed by how late they imposed strict social distancing measures as proxied by stay-athome orders. There are some small differences across state groups. For instance, the earliest policy adopter states (darkest line) tended to experience the largest impacts for each labor market indicator, while states that never imposed restrictions (dashed line) saw milder impacts. These differences are a bit more pronounced in the CES employment and CPS exits series, than the original data we analyzed on postings and claims. However, compared to the overall impacts, the differences between state groups are relatively small. The collapse of the labor market was sudden and severe across all state groups. The series that are available at higher frequencies (UI claims

\footnotetext{
${ }^{2}$ Employment measured in the CES fell by $6.3 \%$ from January 2008 to February 2010.

${ }^{3}$ To define exits, we restrict attention to CPS respondents who were present across adjacent survey months. The exit rate is defined as anyone observed in employment in the previous month and non-employment in the current month, divided by employment in the previous month.

${ }^{3} \mathrm{We}$ obtain state-level COVID cases and the date of state-level stay-at-home policies from the New York Times: https://www.nytimes.com/interactive/2020/us/coronavirus-stay-at-home-order.html and https://github.com/nytimes/covid-19-data.
} 
Figure 1: Labor Market Series by State Policy
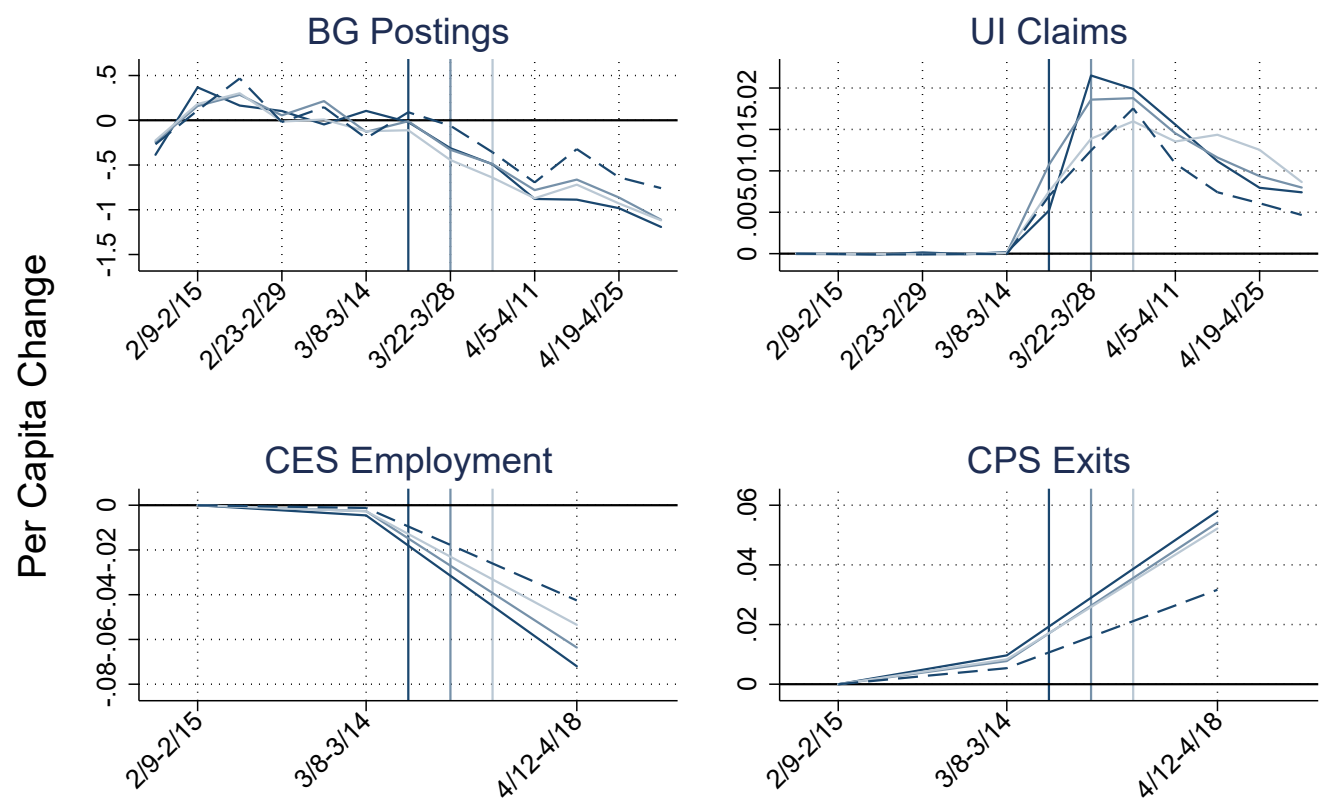

Date

Darker color indicates states with earlier stay-at-home policy adoption.

Note: Vertical lines indicate the first date of stay-at-home orders in the state group, by color. The darkest line includes the first group of states to issue stay-at-home orders, having done so by March 22 (California, Illinois, New York, and New Jersey). The next darkest line includes the vast majority of states, those issuing stay-at-home orders between March 23 and 30, and the lighter line includes states issuing stay-at-home orders most recently (from March 31). The dashed line shows the five states with no such order (Arkansas, Iowa, Nebraska, North Dakota, and South Dakota). All series are the per capita change in postings from the state group-specific average over January 19-Feb 29, 2020. CPS exits are moves from employment in the preceding month to non-employment in the current month.

and job postings) also indicate a high degree of synchronicity across states.

We next consider the relationship between the initial COVID-19 spread and the magnitude of the labor market decline across states. Figure 2 shows the relationships for three of our labor market series and the cumulative number of cases in the week of March 8-14-a period before policy responses might have impacted both the spread of COVID and the labor market.footnotemark

Overall we find that states with more early spread of the virus have worse labor market outcomes. The (population-weighted) best fit lines are all highly statistically significant and imply a one-standard deviation increase in early COVID spread is associated with a roughly one-quarter of a standard deviation change in each of the labor market outcomes.

We conclude that the deterioration of the labor market is a national phenomenon driven by a national crisis. State-level variation in policies seems to have mattered less than the spread of the virus itself combined with increased uncertainty, disrupted supply chains, and the drop in demand for final goods.

\footnotetext{
${ }^{3}$ The CPS exits series contains sample sizes at the state level that are too small to draw inference.
} 
Figure 2: Labor Market Series by State Policy by COVID Spread

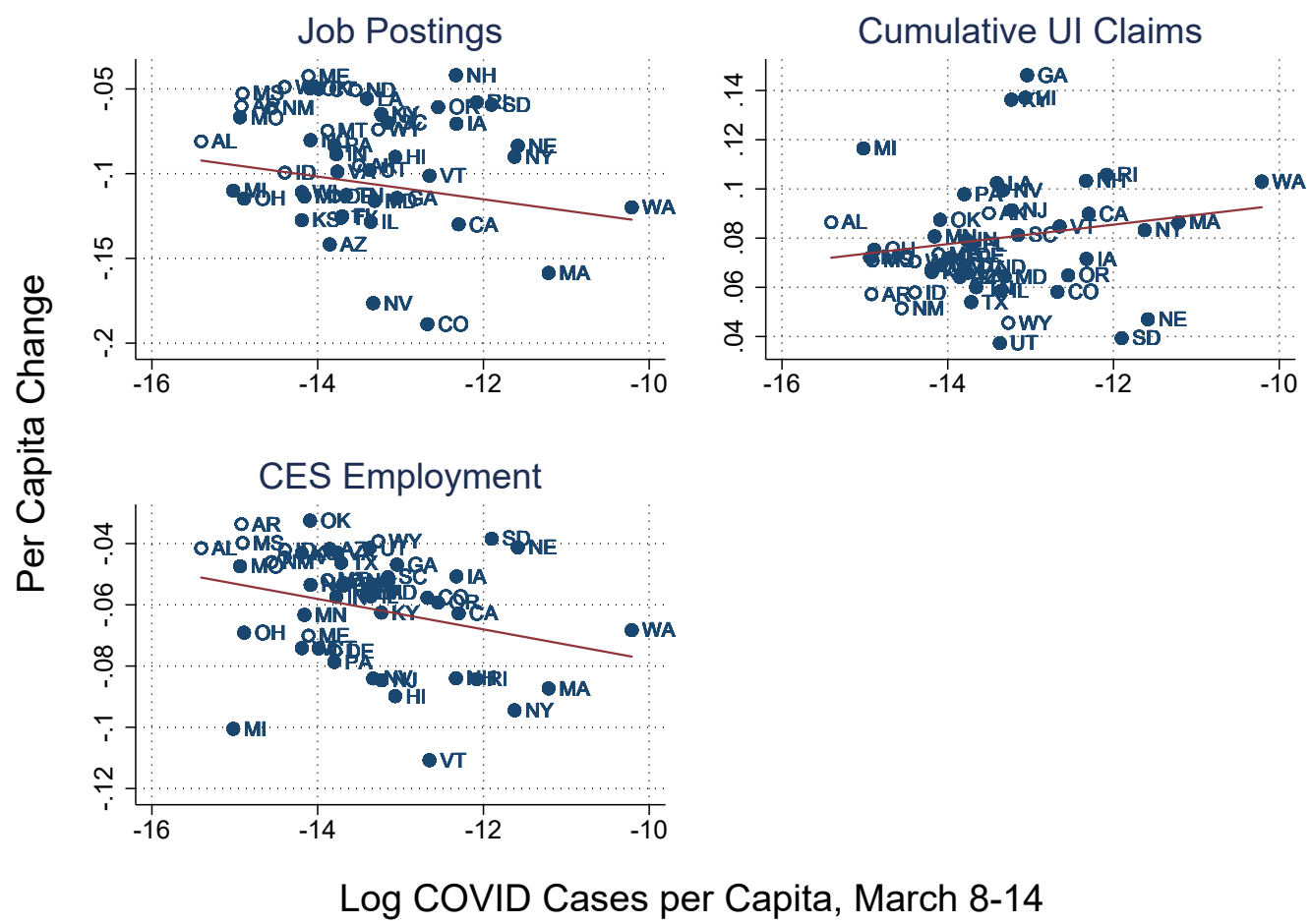

Notes: Variables are the per capita change in the state from January 19-February 29 and March 22-May 2, 2020. Claims are the sum of initial claims over the relevant time period. The best fit lines are population weighted. The $\mathrm{X}$-axis is $\log (1+$ cases $)$ divided by population so that states with no cases as of March 14 are still included and indicated with hollow circles.

\section{Variation across industries}

Figure 3 shows the time pattern for job postings and employment by sector. We separate out "front line" jobs such as those in essential retail and nursing (the latter of which is defined at the occupation level), as well as sectors that proved especially relevant. We define essential industries as in Kahn et al. [2020], which follows as closely as possible the New York State definition. ${ }^{4}$ As a normalization, each series is divided by its February level. Job postings are aggregated to the monthly level to clean out some noise.

Job postings and employment both exhibit steep collapses in labor demand in April. The largest losses were in leisure and hospitality (purple line) and non-essential retail (dashed red). Job postings in each fell below $50 \%$ of their February level, while employment declined by half and a third, respectively. In contrast, postings in essential retail (solid red) increased over March and April, as employers scrambled to meet need, and employment remained relatively flat. For nursing (solid blue, not available for the employment series), the postings decline was somewhat

\footnotetext{
${ }^{4}$ We use Governor Cuomo's list of essential industries for New York State as of March 22, 2020. https://www.governor.ny.gov/news/governor-cuomo-issues-guidance-essential-services-under-new-york-statepause-executive-order.
} 
Figure 3: Job Postings by Sector
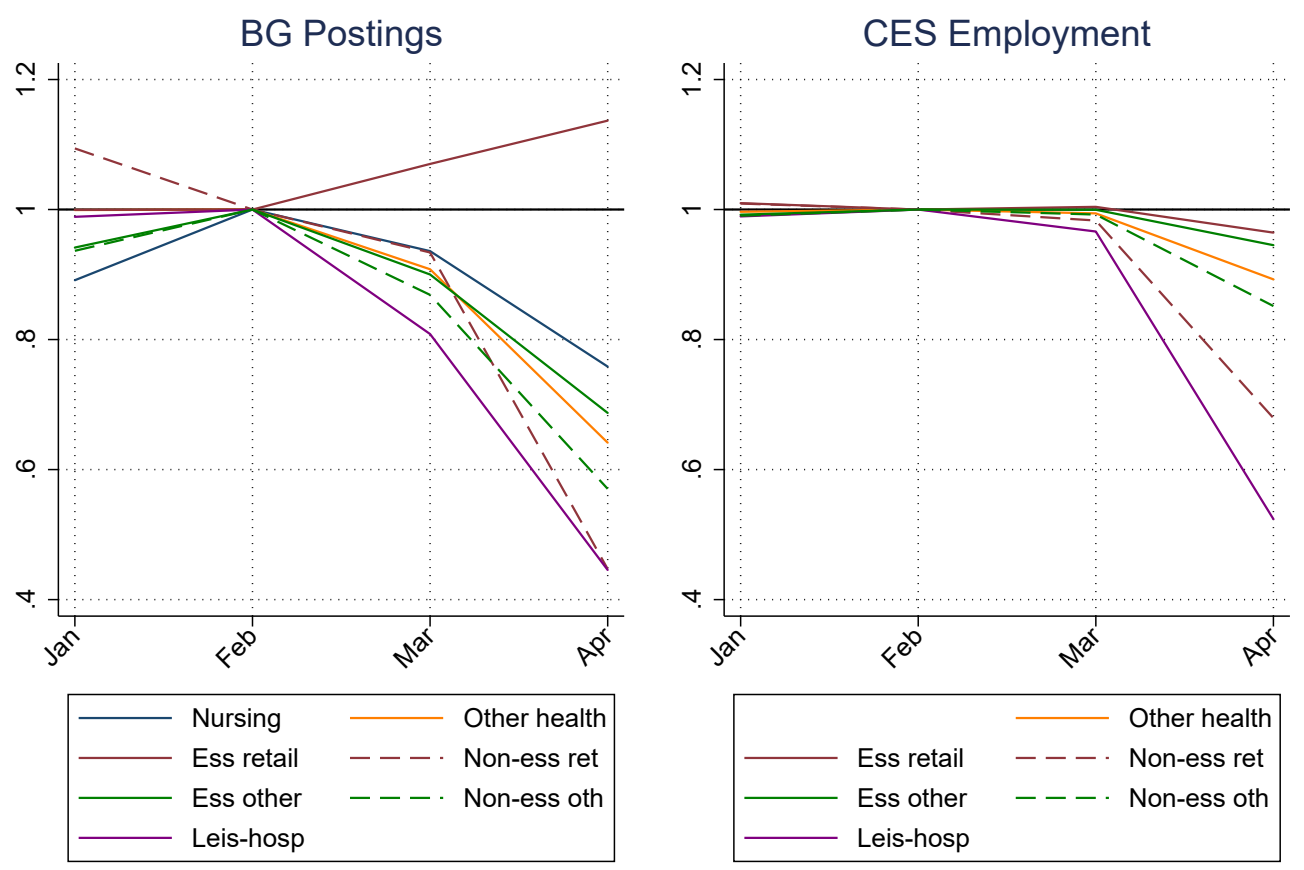

Date

Notes: Postings and employment are divided by the industry or occupation-specific average from February, 2020. Categories are mutually exclusive and exhaustive. Nursing is occupation codes beginning in 291141 (it is not possible to measure occupations for CES employment). Health is NAICS industry code 62. Retail is NAICS code 44-45 and divided into our categorization of essential and non-essential based on New York State guidelines. Leisure and hospital are NAICS codes 71 and 72 .

shallower and slower, but by April the number of ads in nursing dropped to $75 \%$ of its February level. ${ }^{5}$ For healthcare, and other industries, losses are fairly similar. Postings and employment fell by more in non-essential jobs (dashed green line) than in essential jobs (solid green line), as would be expected, with healthcare (orange) in between. All these industries sit between $60 \%$ and $70 \%$ of their February postings level and employment losses total between $5 \%$ and $15 \%$. As a whole, figure 3 presents a clear picture of sharp declines across all types of jobs, with the exception of essential retail.

The UI claims data is not generally available by detailed industry for all states. However, Washington State, uniquely among large states, provides public access to detailed (three-digit) industry and occupation codes, which we need for defining essential industries, and, later, workfrom-home occupations. So we will focus our attention there for claims breakdowns. Because industries are available at only a higher aggregation in the UI claims data, we assign essentialness at the broad sector level. ${ }^{6}$ These series are normalized by taking the difference from the beginning-

\footnotetext{
${ }^{5}$ It is possible that some states allocated or drafted staff into health care, bypassing the traditional hiring procedures. Thus, the numbers for nursing might not be fully representative in this period.

${ }^{6}$ For retail, we define essential as NAICS codes 444, 445, 446, 447, 454, and 452. Otherwise, we classify as essential
} 
of-year average and dividing by employment.

Figure 4 breaks down the rise in Washington's initial UI claims by industries. Consistent with the findings reported using vacancy postings, UI claims in essential retail and nursing rose the least. Further, we see the most substantial deterioration in leisure and hospitality and non-essential retail, with the former spiking a week before the rest.

It should be emphasized, however, that even nursing and essential retail saw claims increase by orders of magnitude, and these groups are only a small fraction of the labor force. So despite meaningful differences across industries, overall, UI claims in Washington show broad-based increases across both essential and non-essential industries, as well as those in healthcare.

The CPS series on exits validates the Washington State claims analysis. The dots in Figure 4 show the rate of separations from employment to non-employment for the same industry groupings. ${ }^{7}$ They show an identical ordering, with leisure/hospitality and non-essential retail suffering the largest losses and nursing and essential retail showing the smallest. The magnitudes are also important, with separation rates slightly elevated in March and more than twice as high in April as in February for nearly all industries (see Appendix Figure A.1 for observations earlier in 2020).

The spike in initial claims in essential retail and nursing, along with the smaller or lack of decline in postings suggests substantial reallocation in these areas. That is, essential retail and nursing likely saw a great deal of churn, with many workers being sent to unemployment even while employers wished to maintain hiring.

\section{Variation by work-from-home capability}

The stay-at-home directives make it nearly impossible for non-essential workers who cannot work from home to keep up their work. Researchers estimate that only about a third of workers have jobs where work from home is possible [Dingel and Neiman, 2020], and we find that this proportion is similar across essential and non-essential sectors, excluding health [Kahn et al., 2020].

Figure 5 shows postings and employment (left panel) and claims and CPS exits (right panel) by work from home capability using the recent classification of Dingel and Neiman [2020]. ${ }^{8}$ The claims data are again Washington State because they make available data at the 3-digit occupation level. The ability to work from home is defined using tasks, which are a feature of the occupation. CES employment data do not include series by occupations, so we instead use CPS data, even though the sample sizes are smaller.

Beginning with the right panel, we find that UI claims increased by more for those who are

agriculture (naics code 11), utilities (22), construction (23), wholesale (42), transportation and warehousing (48-49), information (51), finance (52), administrative support (56), food and accommodation (72), and public administration (92). Health (62) is essential but usually broken out separately.

${ }^{7}$ We position them at the CPS interview reference week. To make the scale comparable to UI claims, we divide by $\frac{52}{12}$, which represents the average weekly separation rate over the prior period.

${ }^{8}$ Dingel and Neiman [2020] use O*NET to classify occupations where telework is very likely not possible. They use a range of criteria including work contexts and activities that involve physical movement, risk of injury, use of protective equipment, operating or repairing machines or equipment, etc. We find similar results when we simply use the $\mathrm{O}^{*} \mathrm{NET}$ occupation score on whether physical proximity is required. 
Figure 4: Washington State initial UI claims (lines) and CPS Exits (dots)

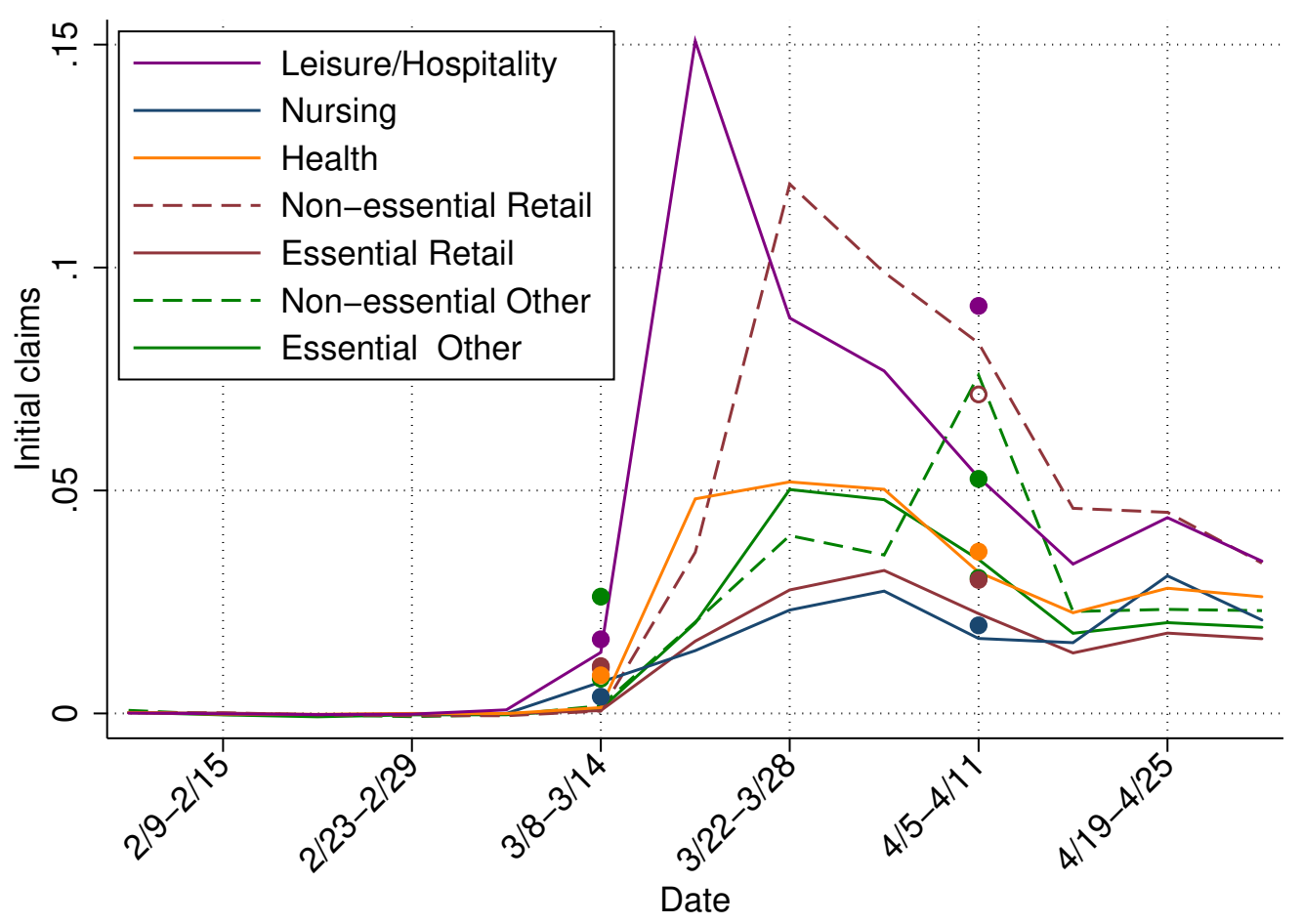

Note: We normalize claims and exits by industry or occupation-specific employment and take the difference relative to the average from January 19-Feb 29, 2020. For CPS exits, groupings are mutually exclusive and exhaustive. For UI claims, the industries are mutually exclusive, but Nursing is occupation SOC 291 and also contained in the other groups. For comparison, the CPS employment-to-non-employment separation rates in March and April are converted to weekly rates and included as dots. 
not able to work from home. Initial claims rose about two-thirds as much for occupations that are work-from-home capable. This pattern is consistent with CPS employment separations, shown as dots in the figure on the interview reference week, and also high-frequency survey evidence from Adams-Prassl et al. [2020].

Interestingly, postings tell a somewhat different story. The left panel shows how postings varied with whether an occupation is suitable for work-from-home and whether the industry is considered essential. We find that postings fell by a similar amount in non-essential industries (dashed lines), regardless of whether work-from-home was likely possible. In essential sectors, the non work-fromhome capable occupations saw a somewhat smaller decline in posted, likely driven by essential retail, as noted earlier. CPS employment data (dots) indicate smaller declines in work-from-home jobs, regardless of whether they are essential (blue), and the largest collapse in non-work-from-home non-essential jobs (hollow maroon dot).

As a whole, all series show large collapses in the labor market, regardless of work-from-home capability. While the employment and separations series show that employers shed more workers who are not able to work from home, vacancy postings declined by a similar amount in occupations suitable for work-from-home. The reduction in vacancies leads us to expect work-from-home occupations to show weakness in excess of that indicated by UI claims in the coming months. The separation shock may have been less acute for these occupations, but the decline in vacancies suggests that those occupations that do lend themselves to work-from-home will not add workers in coming months.

Figure 5: Labor Market Outcomes by Work From Home Capability
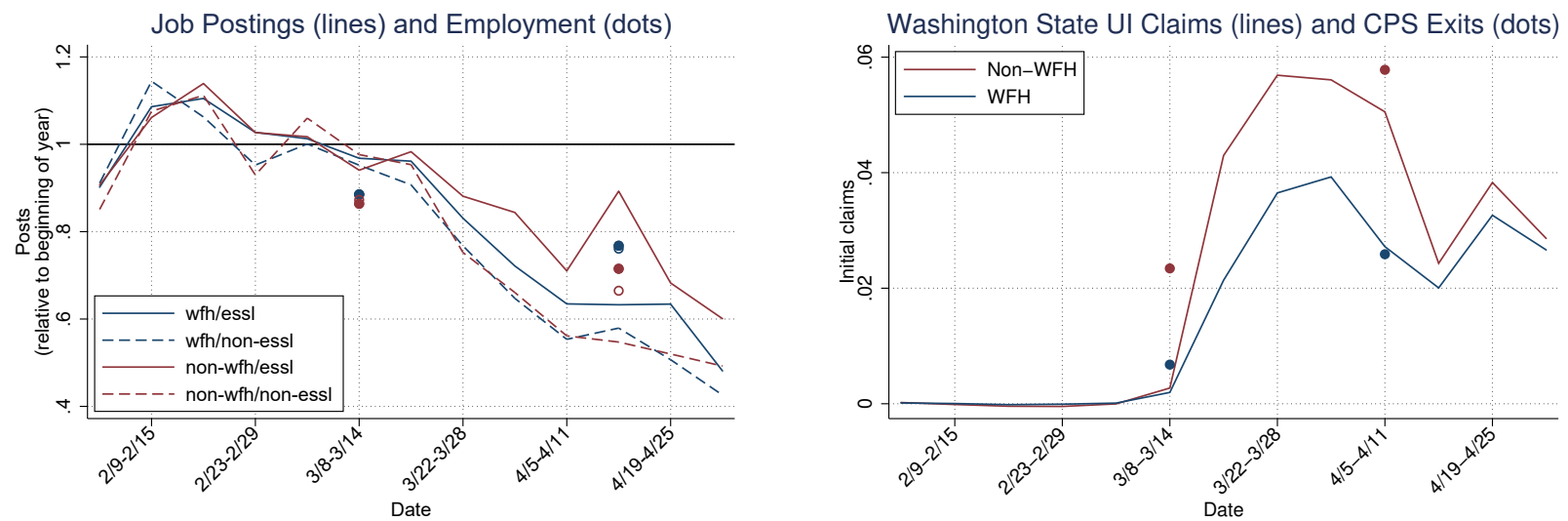

Notes: Postings (left panel) are divided by group-specific average from January 19-February 29, 2020. Categories are mutually exclusive and exhaustive. Work-from-home (wfh) measures are assigned at the occupation level using Dingel and Neiman [2020]. Claims and exits (right panel) are computed as percent of employment in that occupation group and differenced from the group-specific average from January 19-Feb 29, 2020. Claims are not available for industry-by-occupation categories so we cannot break down wfh by whether the industry is essential. In the right panel, the CPS employment separation rates in March and April are converted to weekly rates and included as dots.

Overall, we interpret the large deterioration in labor market conditions across the board, re- 
gardless of work-from-home capability, as another sign that the deterioration in the labor market is broad based and affects all sectors, regardless of their exposure to direct restrictions on labor. UI claims suggest that work-from-home capability provides some shelter from job loss, but employment is likely to fall among these occupations as well, as separation rates in those occupations are still multiples higher than any previous recession and vacancy postings suggest hiring will contract.

As a whole, our analysis of postings and claims across industries and occupations illustrate the incredible labor reorganization occurring because of simultaneous supply and demand shocks. While occupations that are work-from-home capable may be insulated from some of the labor demand shocks stemming from stay-at-home orders, they still suffer from the negative aggregate demand shock stemming from the crisis. At the same time, labor in occupations that cannot be done from home have in addition been subject to a shock in demand due to the restriction on the ability to work from home. This shock is evidenced in the larger increase in UI claims (see figure 4) compared to those occupations that can be performed from home. The vacancy data however shows strong declines in the demand for labor in all occupation as aggregate demand contracts. All this is happening while the demand for labor has shifted towards the front-line services of essential retail.

\section{Conclusion}

We have presented statistics from UI claims and from vacancy postings obtained from Burning Glass Technologies on the evolution of the labor market over the course of the COVID-19 crisis.

The labor market is currently experiencing unprecedented weakness. We observe broad-based declines in job postings and spikes in insurance claims across states, sectors, and occupations. Essential retail and nursing are exceptions in that job postings have mainted their level or exhibited a shallow drop, even while they have seen large spikes in claims. As a result, these areas will see a great deal of churn, with many workers being sent to unemployment even while employers desire to maintain hiring.

Work-from-home occupations have been somewhat sheltered from immediate unemployment, exhibiting less than half the rate of increase as non-work-from-home occupations in Washington State. However, given the large decline in job postings for work-from-home occupations, we expect these area to show weakness in excess of that indicated by unemployment insurance claims in the coming months. That is, these areas still suffer from the negative aggregate demand shock stemming from the crisis.

We have also been able to validate our analyses using the more traditional BLS data sources that were released at a longer lag. Interestingly, the data sources largely agree with each other. This gives us confidence moving forward that job vacancies and UI claims paint a fairly representative picture. Even though they are less traditional data sources, they are available at much higher frequenecy, and, in the case of Burning Glass job vacancies, at much richer detail.

The broad based nature of the collapse in vacancy postings and spikes in claims suggest the 
current damage is not solely caused by stay-at-home orders; it is too large and pervasive. There are similar effects on directly restricted and only indirectly affected sectors. Just as employers across the nation reduced hiring and began to lay off workers at about the same time - regardless of the specific stay-at-home orders in their state - lifting the stay-at-home orders does not necessarily or automatically change the outlook for demand of products and services. Customers are likely to remain cautious, companies my be reluctant to act too quickly, and interruptions in global or national supply chains are likely to continue while the risks of viral outbreaks remain. Consistent with the notion that the virus itself is the culprit of the disruption, rather than state restrictions, we do see modest evidence that early COVID spread predicts the magnitude of the labor market collapse in the state. We therefore conclude that the damage to the economy is unlikely to be undone simply by lifting the stay-at-home orders. 


\section{References}

Adams-Prassl, Abi, Teodora Boneva, Marta Golin, and Christopher Rauh, "Inequality in the Impact of the Coronavirus Shock: Evidence from Real Time Surveys," 2020. Unpublished Manuscript available at https://drive.google.com/file/d/1JYI4bzQ5ytmml $c t 8 o-$ Zw7BqRsHKzsq/view.

Baek, C, Peter B McCrory, Todd Messer, and Preston Mui, "Unemployment effects of stayat-home orders: Evidence from high frequency claims data," Working Paper 101-20, Institue for Research on Labor and Employment 2020.

Baker, Scott R, Nicholas Bloom, Steven J Davis, and Stephen J Terry, "COVID-Induced Economic Uncertainty," Working Paper 26983, National Bureau of Economic Research April 2020.

Barrero, Jose Maria, Nicholas Bloom, and Steven J Davis, "COVID-19 Is Also a Reallocation Shock," Working Paper 27137, National Bureau of Economic Research May 2020.

Bartik, Alexander W, Marianne Bertrand, Zoë B Cullen, Edward L Glaeser, Michael Luca, and Christopher T Stanton, "How Are Small Businesses Adjusting to COVID-19? Early Evidence from a Survey," Working Paper 26989, National Bureau of Economic Research April 2020.

Blandin, Adam and Alexander Bick, "Real Time Labor Market Estimates During the 2020 Coronavirus Outbreak," 2020. Unpublished Manuscript available at https://drive.google.com/file/d/1GzjndWkWxfDbCzkNGCpWHxaghpwshAkv/view.

Blank, Rebecca and David Card, "Recent Trends in Insured and Uninsured Unemployment: Is There An Explanation?," The Quarterly Journal of Economics, 1991, 106 (4), 1157-1189.

Cajner, Tomaz, Leland D Crane, Ryan A Decker, John Grigsby, Adrian HaminsPuertolas, Erik Hurst, Christopher Kurz, and Ahu Yildirmaz, "The U.S. Labor Market during the Beginning of the Pandemic Recession," Working Paper 27159, National Bureau of Economic Research May 2020.

Campello, Murillo, Gaurav Kankanhalli, and Pradeep Muthukrishnan, "Corporate Hiring under COVID-19: Labor Market Concentration, Downskilling, and Income Inequality," Working Paper 27208, National Bureau of Economic Research May 2020.

Coibion, Olivier, Yuriy Gorodnichenko, and Michael Weber, "Labor Markets During the COVID-19 Crisis: A Preliminary View," Working Paper 27017, National Bureau of Economic Research April 2020.

Cortes, Guido Matias and Eliza C. Forsythe, Technical Report.

Dalton, Michael R., Lisa B. Kahn, and Andreas I. Mueller, "Do online job postings capture job vacancies? An analysis of matched online postings and vacancy survey data," Mimeo, 2020.

Dingel, Jonathan I. and Brent Neiman, "How Many Jobs Can be Done at Home?," Working Paper 26948, National Bureau of Economic Research April 2020.

Gupta, Sumedha, Laura Montenovo, Thuy D Nguyen, Felipe Lozano Rojas, Ian M Schmutte, Kosali I Simon, Bruce A Weinberg, and Coady Wing, "Effects of Social Distancing Policy on Labor Market Outcomes," Working Paper 27280, National Bureau of Economic Research May 2020.

Hassan, Tarek Alexander, Stephan Hollander, Laurence van Lent, and Ahmed Tahoun, "Firm-level Exposure to Epidemic Diseases: Covid-19, SARS, and H1N1," Working Paper 26971, National Bureau of Economic Research April 2020.

Hensvik, Lena, Thomas Le Barbanchon, and Roland Rathelot, "Job Search during the 
COVID-19 Crisis," CAGE Online Working Paper Series 473, Competitive Advantage in the Global Economy (CAGE) 2020.

Hershbein, Brad and Lisa B. Kahn, "Do Recessions Accelerate Routine-Biased Technological Change? Evidence from Vacancy Postings," American Economic Review, July 2018, 108 (7), 173772 .

Kahn, Lisa B., Fabian Lange, and David Wiczer, "Labor Supply In The Time of COVID19," mimeo, March 2020.

Kudlyak, Marianna and Erin Wolcott, "Pandemic Layoffs," May 2020. 


\section{A Online Appendix}

Figure A.1: Labor Market Series through May 2, 2020
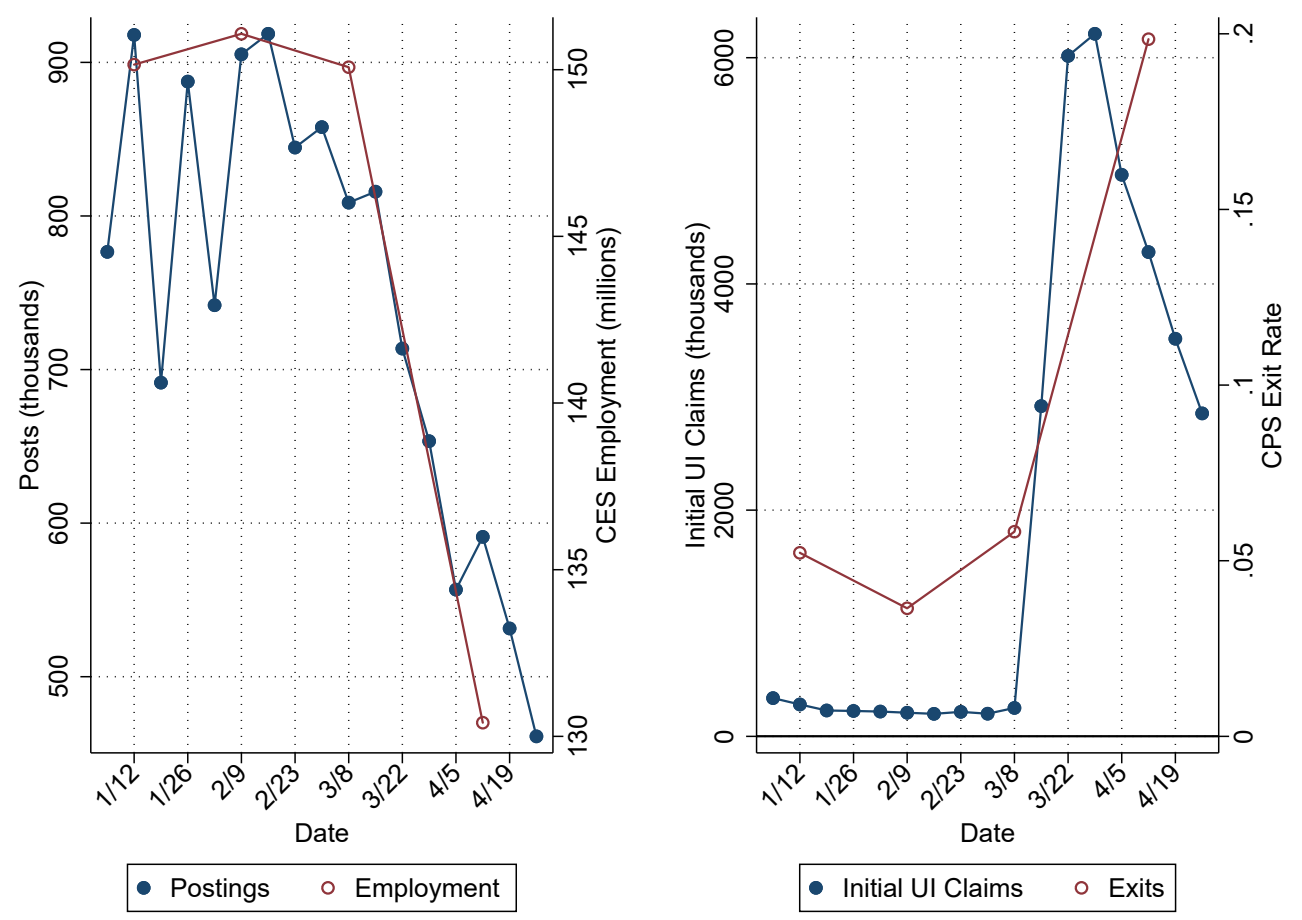

Note: Job postings are the total number of new vacancies each week in the Burning Glass Technologies' online postings database. Employment is measured using the Current Employment Statistics and refers to total payroll in the week containing the 12th for each month. Unemployment insurance initial claims data are obtained from FRED and the Bureau of Labor Statistics. Exit rate refers to the rate of exits from employment to non-employment over the month. It is measured using Current Population Survey longitudinally linked data and defined as the number of people who were employed in the previous month and not employed in current month, divided by previous month employment. 